\title{
Utilization of Calcined Gypsum in Water and Wastewater Treatment: Removal of Phenol
}

\author{
Chinenye Adaobi Igwegbe', Aiman Eid Al-Rawajfeh ${ }^{2 *}$, H.I. Al-Itawi' ${ }^{2}$ S. Sharadqah², \\ Shahd Al-Qazaqi ${ }^{2}$, Esraa Abu Hashish ${ }^{2}$, Malak Al-Qatatsheh ${ }^{3}$, Mika Sillanpaa ${ }^{4}$ \\ 1 Department of Chemical Engineering, Nnamdi Azikiwe University, Awka, Nigeria \\ 2 Tafila Technical University (TTU), Department of Chemical Engineering, P.O. Box 179, 66110 Tafila, Jordan \\ 3 Tafila Technical University (TTU), Department of Chemistry, Tafila, Jordan \\ ${ }^{4}$ Department of Green Chemistry, Lappeenranta University of Technology, Sammonkatu 12, FI-50130 Mikkeli, \\ Finland \\ * Corresponding author's e-mail: aimanr@yahoo.com
}

\begin{abstract}
The release of phenol-containing effluents above the phenol permissible limit has triggered a lot of concern over the world due to their toxic nature. The adsorptive potential of gypsum on the removal of phenol was investigated. The effect of gypsum loading (0.5-3 g), contact time (2.5-20 min) and solution temperature ( 298 to $318 \mathrm{~K}$ ) on the removal of phenol by gypsum was studied at neutral $\mathrm{pH}$. The thermodynamics of the adsorption process was also studied. The kinetic data were fitted into the pseudo-second-order, Elovich, and intraparticle diffusion models. The removal efficiency of phenol increased along with the mass of gypsum, contact time and temperature. The results of the thermodynamics study indicate that the adsorption process is spontaneous and endothermic in nature. The change in free energy $\left(\Delta G^{0}\right)$ was found to increase with temperature. The values of the estimated $\Delta G^{0}$ suggest that the phenol adsorption on gypsum is a physical adsorption process. Additionally, the kinetic data fitted best into the pseudo-second-order than the other kinetic models. This study proved that phenol can be used effectively for the reduction of phenol concentrations in water and wastewater.
\end{abstract}

Keywords: calcined gypsum; phenol; removal; thermodynamics parameters.

\section{INTRODUCTION}

The excessive release of phenol-containing wastes into the aqueous ecosystem due to industrialization is one of the greatest threats to health (Bemosmane et al., 2018; Pourakbar et al., 2018; Kaczorek et al., 2016). The major sources of phenolic compounds include the wastes from paper mills, pesticides production, petrochemical, paint, textile plants, oil refineries, and pharmaceutical industries (Mahvi et al., 2007; Azevedo et al., 2009,Baird; 1998). Phenols and phenolic compounds are considered as the priority and one of the most dangerous pollutants since they are harmful to organisms even at a low concentration (Rahmani et al. 2008; Pourakbar et al., 2018). Phenol and its degradation products are major aquatic pollutants since they are toxic and carcinogenic in nature (Ahmadi and Igwegbe, 2018; Kulkarni and Kaware, 2013). Phenol is lethal to people and can result in either acute (short-term) and chronic (long-term) effects (Villegas et al., 2016). It is highly corrosive and causes harmful side effects such as diarrhea, nervous breakdown, impaired vision, sour mouth, and excretion of dark urine (Kulkarni and Kaware, 2013). Besides, it is relatively stable and soluble in water (Azevedo et al., 2009. Therefore, considering the health implication, proper treatment techniques are necessary for the reduction of the phenol level. Owing to its high toxicity and difficulty to reduce biologically, the limits for their existence in drinking water and effluents were set up (Sharan et al., 2009; Roostaei and Tezel, 2004; Salari et al., 2018). The 
United States Environmental Protection Agency (USEPA) specified that the phenol concentration in drinking water and industrial effluents must be less than $1 \mu \mathrm{g} / \mathrm{L}$ and $500 \mu \mathrm{g} / \mathrm{L}$, respectively (Tao et al., 2013; Yan et al. 2006; Salari et al., 2018; Wu et al; 2001). Additionally, the World Health Organization (WHO) considers the maximum permissible limit of phenol in drinking water to be $0.002 \mathrm{mg} / \mathrm{L}$ (Salari et al., 2018; Roostaei et al., 2004). Furthermore, the EPA has set the concentration of phenol in wastewater below $2 \mathrm{mg} / \mathrm{L}$ (EPA, 2015; Pourakbar et al., 2018). The presence of phenol in water contributes to taste deterioration and odor (Sharan et al., 2009; Uddin et al., 2008; Moustafa et al. 1989). It has been reported that 700 million tons of phenol are produced per annum (Senthilvelan et al., 2014).

Many methods have been employed for the reduction of phenol including chemical oxidation (Kumar et al., 2010; Yavuz et al., 2007), photodegradation (Wu et al., 2001; Mahvi et al., 2007; Azevedo et al., 2009), ion exchange (Caetano et al., 2009), electrocoagulation (Zazouli and Taghavi, 2012; Olya and Pirkarami, 2013; Bazrafshan et al., 2012), adsorption (Gholizadeh et al., 2013; Feng et al., 2015; Ahmadi and Igwegbe, 2018; Roostaei and Tezel, 2004), coagulation-flocculation (Bazrafshan et al., 2012), membrane filtration (Bemosmane et al., 2018), advanced oxidation processes (Rubalcaba et al., 2007; Esplugas et al., 2002), and other.

However, amongst the above-mentioned methods, the adsorption process seems to be the most prospective for the removal of organic and mineral pollutants (Sarvani et al., 2018; Deng et al., 2010) and is effective either carried out on laboratory or industrial scale (Sarvani et al., 2018; Rodrigues, 2011). Adsorption has been extensively used to control the phenol pollution because of its cost-effectiveness, simplicity of operation, availability of adsorbent precursors and efficiency (Menkiti et al., 2018). Activated carbon is commonly used for adsorbing pollutants but it is very expensive and cannot be easily regenerated (Khoshnamvand et al., 2017). Ahmadi and Igwegbe (2018) studied the removal of phenol using acid-modified bentonite. The removal efficiency of $97.9 \%$ was obtained at contact time of $60 \mathrm{~min}$, dosage of $0.6 \mathrm{~g} / \mathrm{L}, \mathrm{pH}$ of 6 and concentration of $50 \mathrm{mg} / \mathrm{L}$; the experimental data was best described by the pseudo-secondorder kinetic model. Menkiti et al. (2018) used chemically modified Nteje clay (CMC) to remove phenol from petroleum effluent; $91.67 \%$ efficiency was reached at equilibrium time of $25 \mathrm{~min}$ and $\mathrm{pH}$ of 6 . The data fitted best to the Langmuir and pseudo-second-order model with monolayer adsorption capacity of $3.487 \mathrm{mg} / \mathrm{g}$. Other researchers utilized low-cost adsorbents for the removal of phenol such as pomegranate peel carbon (Afsharnia et al., 2016), Moringa peregrine tree shell ash (Zarei et al., 2013), bentonite (Senturk et al., 2009; Banat et al., 2000), charcoal (Halhouli et al., 1995; Mukherjee et al., 2007), bagasse fly ash (Srivastava et al., 2006), freshwater microalgae Chlorella vulgaris (Baldiris - Navarro et al., 2018), tobacco residues (Kilic et al., 2011), Moroccan stevensite (Hamadaoui et al., 2018), sawdust (Dakhil, 2013; Douara et al, 2016), avocado kernel seeds (Rodrigues et al., 2011), water hyacinth (Uddin et al., 2008) and ostrich feathers (Monshouri et al., 2012).

Gypsum is more advantageous compared to other adsorbents because of its abundance in nature, low-cost and no pretreatment is required as an adsorbent (Rauf et al., 2009). Gypsum $\left(\mathrm{CaSO}_{4} \cdot 2 \mathrm{H}_{2} \mathrm{O}\right)$ is a very soft sulfate mineral composed of calcium sulfate dihydrate (Bello et al., 2013; Cornelis and Cornelius, 1985). Gypsum was applied successfully and extensively for the removal of dye (Rauf et al, 2009), pharmaceutical drugs (Li et al., 2014) and heavy metals (Petruzzeli et al., 2015; Raii et al., 2014). Moreover, there is no report on the use of gypsum for the removal of phenol.

The present study aims at investigating the removal of phenol from aqueous solution using gypsum which is abundantly available. The effects of mass of adsorbent (gypsum), contact time and solution temperature on the removal of phenol were investigated using the batch method under neutral $\mathrm{pH}$ conditions. The thermodynamics and kinetics of the adsorption process were also studied.

\section{MATERIALS AND METHODS}

The gypsum was supplied by Rawabi for Mining (Tafila, South Jordan). It was crushed, milled and then calcined at $150-200^{\circ} \mathrm{C}$. Phenol (99\% purity) was obtained from a local supplier. Phenol stocks were prepared by dissolving accurate weight of phenol in $1000 \mathrm{~mL}$ of DDW. This stock solution was then used in the preparation of synthetic wastewater samples with different concentrations. The batch sorption experiments 
were conducted in a series of $500-\mathrm{mL}$ glass beakers containing $250 \mathrm{~mL}$ of the phenol solution. A determined amount of calcined gypsum $(0.5-3.0 \mathrm{~g})$ was added to these beakers. The experiments were conducted at an ambient temperature of $25^{\circ} \mathrm{C}$ and the desired temperature with a stirring time of 5-25 min. After the completion of the experiments, the samples were filtered. The filtrate of phenol solutions was then subjected to UV-visible analysis in order to determine the percentage of phenol removal (SPECTRACOMP 602; Advanced Products, Milan, Italy). A calibration curve of absorbance against different concentrations of phenol was constructed. The samples of phenol solutions had been analyzed by UV before and after treatment in order to determine the amount of phenol removed. The amount of phenol adsorbed on gypsum, $q_{e}(\mathrm{mmol} / \mathrm{g})$ and the percentage of phenol removed $(\% R)$ were calculated as follows (Igwegbe et al., 2016; Ahmadi and Igwegbe, 2018):

$$
\begin{gathered}
q_{e=\left(C_{0}-C_{t}\right) \times \frac{V}{M}} \\
\% R=\frac{C_{0}-C_{t}}{C_{0}} \times 100
\end{gathered}
$$

where: $C_{0}$ and $C_{t}(\mathrm{mg} / \mathrm{L})$ are the concentrations at the initial time,

$t=0$ and time, $t$, respectively.

$V$ is the volume of phenol solution (L) and

$W$ is the mass of gypsum (g).

\section{RESULTS AND DISCUSSION}

\section{Effect of gypsum mass}

The effect of gypsum mass on the reduction of phenol concentration was studied by varying the mass at the initial phenol concentration of $0.3809 \mathrm{~mol} / \mathrm{L}$. As seen in Fig. 1 and Table 1, as the mass of gypsum was increased from 0.5 to $3 \mathrm{~g}$, the percentage of phenol removed on the adsorbent (gypsum) was enhanced steeply from 29.06 to $84.25 \%$. Therefore, the maximum phenol removal was achieved at the highest mass of gypsum studied ( $3 \mathrm{~g})$. The improvement in phenol removal with increasing mass of gypsum is as a result of the increase in the number of adsorption sites and adsorbent surface area (Sahu et al., 2017; Afsharnia et al., 2017). The amount of phenol per unit mass of the gypsum, $q_{e}$ decreased with the increasing adsorbent loading from 177.75 to $31.28 \mathrm{mmol} / \mathrm{g}$. This is because the active adsorption sites of the adsorbent were not fully exploited (unsaturated) at a higher adsorbent loading compared to lower adsorbent mass (Gorzin and Abadi, 2018; Radnia et al., 2012). A smaller mass of adsorbent will be saturated more quickly than a larger one (Larous and Meniai, 2012).

\section{Effect of contact time}

In order to investigate the effect of time on the adsorption of phenol using gypsum, the time of contact varied from 2.5 to 20 min using an

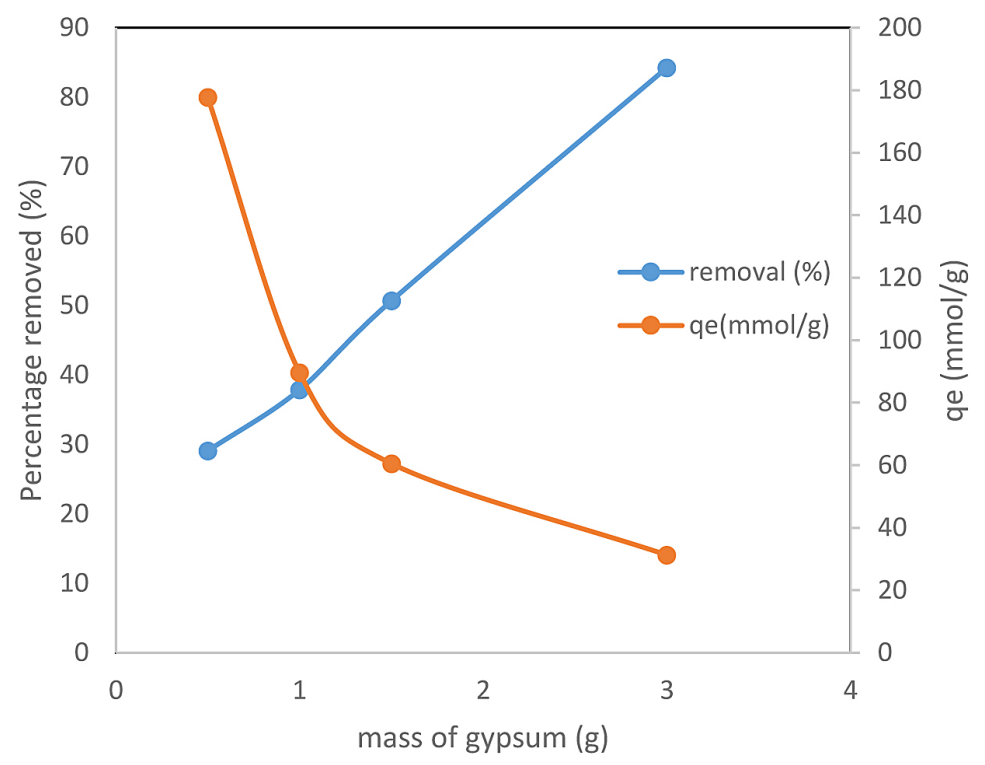

Fig. 1. Effect of mass of gypsum on phenol removal

$\left(\right.$ Contact time $=5 \mathrm{~min}$, temperature $=25^{\circ} \mathrm{C}$, initial phenol concentration $=0.3809 \mathrm{~mol} / \mathrm{L}, \mathrm{pH}=7$ ) 
Table 1. Effect of gypsum mass, contact time and temperature on phenol removal at $\mathrm{C}_{0}=0.3809 \mathrm{~mol} / \mathrm{L}$

\begin{tabular}{|l|c|c|c|c|}
\hline \multicolumn{2}{|c|}{ Operating parameter } & $C_{e}(\mathrm{~mol} / \mathrm{L})$ & Phenol removal $(\%)$ & $q_{e}(\mathrm{mmol} / \mathrm{g})$ \\
\hline \multirow{4}{*}{ Mass of gypsum } & $0.5 \mathrm{~g}$ & 0.2702 & 29.06 & 177.75 \\
\cline { 2 - 5 } & $1 \mathrm{~g}$ & 0.2367 & 37.86 & 89.65 \\
\cline { 2 - 5 } & $1.5 \mathrm{~g}$ & 0.1879 & 50.67 & 60.53 \\
\cline { 2 - 5 } Contact time & $3 \mathrm{~g}$ & 0.06 & 84.25 & 31.28 \\
\hline \multirow{5}{*}{ Temperature } & $2.5 \mathrm{~min}$ & 0.323 & 15.20 & 9.65 \\
\cline { 2 - 5 } & $10 \mathrm{~min}$ & 0.2052 & 46.13 & 43.67 \\
\cline { 2 - 5 } & $20 \mathrm{~min}$ & 0.1189 & 68.78 & 35.55 \\
\cline { 2 - 5 } & $298 \mathrm{~K}$ & 0.1676 & 556 & 43.83 \\
\cline { 2 - 5 } & $308 \mathrm{~K}$ & 0.1179 & 69.05 & 44.68 \\
\hline
\end{tabular}

adsorbent mass of $1.5 \mathrm{~g}$. Figure 2 and Table 1 show that the percentage of phenol removed and the adsorption capacity $q_{e}$ was increased rapidly with time. Maximum phenol removal was attained at the highest contact time studied. This may result from the fact that the frequency of collision of the adsorbate and the adsorbent was increased with retention time, which also increased the process of adsorption (Ahmadi and Igwegbe, 2018; Buhani et al., 2018). Moreover, the adsorption sites were more available with time.

\section{Effect of solution temperature}

Temperature changes the adsorption capacity of an adsorbent for a specific adsorbate (Banerjee and Chattopadhyaya, 2017). The influence of solution temperature on the phenol removal was investigated by varying the temperatures from 298 to 318 K (Fig. 3). As shown in Figure 3 and Table 1, the adsorption of phenol on gypsum was improved with increasing temperature. The highest removal of $70.39 \%$ was achieved at the highest studied temperature of $318 \mathrm{~K}$. The removal of phenol was favored at a higher temperature because temperature increases the number of collisions between the adsorbent and the adsorbate, thereby enhancing the rate of adsorption (Afsharnia et al., 2017). Figure 3 also shows that the amount of phenol uptake by gypsum increased from 35.55 to $44.68 \mathrm{mmol} / \mathrm{g}$. The rate of diffusion of the phenol molecules onto the gypsum surface was high with increased temperature.

\section{Thermodynamics studies}

The thermodynamic parameters including Gibbs free energy change $\left(\Delta \mathrm{G}^{0}\right)$, entropy change

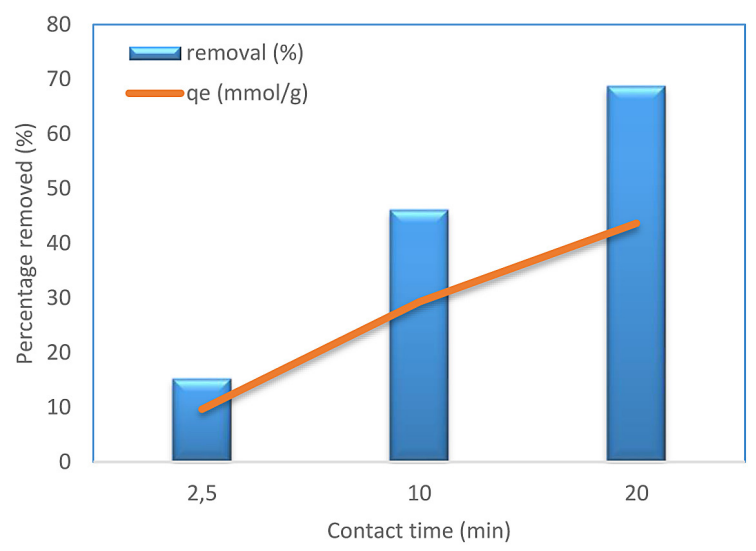

Fig. 2. Effect of contact time on phenol removal

(Mass of gypsum $=1.5 \mathrm{~g}$, temperature $=25^{\circ} \mathrm{C}$, initial phenol concentration $=0.3809 \mathrm{~mol} / \mathrm{L}, \mathrm{pH}=7$ )

$\left(\Delta \mathrm{S}^{0}\right)$ and enthalpy change $\left(\Delta \mathrm{H}^{0}\right)$ were calculated using Eqs. 3 and 4 (Adeogun and Balakrishnan, 2015; AlOthman et al., 2014):

$$
\begin{gathered}
\Delta G^{0}=-R T \operatorname{Ln} K_{d} \\
L n K_{d}=-\frac{\Delta H^{0}}{R T}+\frac{\Delta S^{0}}{R}
\end{gathered}
$$

where: $K_{d}$ is a thermodynamic equilibrium constant obtained using Eq. 3 (Sogut and Caliskan, 2017):

$$
K_{d}=\frac{C_{0}-C_{e}}{C_{e}}
$$

where: $\Delta G^{0}$ is the free energy change $(\mathrm{kJ} / \mathrm{mol})$, $T$ is the solution temperature $(\mathrm{K})$, $R$ is the ideal gas constant $(8.314 \mathrm{~J} / \mathrm{K} /$ mol),

$C_{0}$ is the initial phenol concentration and $C_{e}$ is the final phenol concentration. 


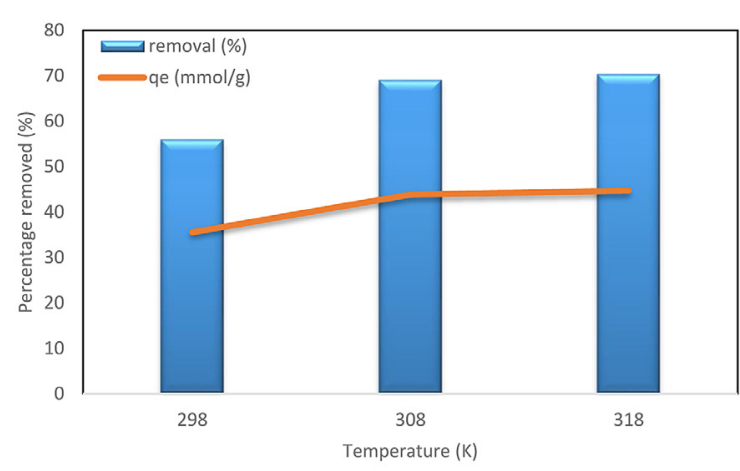

Fig. 3. Effect of solution temperature on phenol removal

(Mass of gypsum $=1.5 \mathrm{~g}$, contact time $=5 \mathrm{~min}$., initial phenol concentration $=0.3809 \mathrm{~mol} / \mathrm{L}, \mathrm{pH}=7$ )

The values of $\Delta H^{0}$ and $\Delta S^{0}$ were obtained from the slope $\left(-\frac{\Delta H^{0}}{R}\right)$ and intercept $\left(\frac{\Delta S^{0}}{R}\right)$ of the Vant Hoff's plot of $L n K_{d}$ versus 1/T (Fig. 4). The calculated thermodynamic parameters are presented in Table 2. The negative value of $\Delta \mathrm{G}^{0}$ indicates the spontaneous nature of the adsorption of phenol on gypsum. The value of $\Delta \mathrm{G}^{0}$ was found to increase along with temperature, which implies that the adsorption of phenol on gypsum was favored at increasing temperature. In general, the free

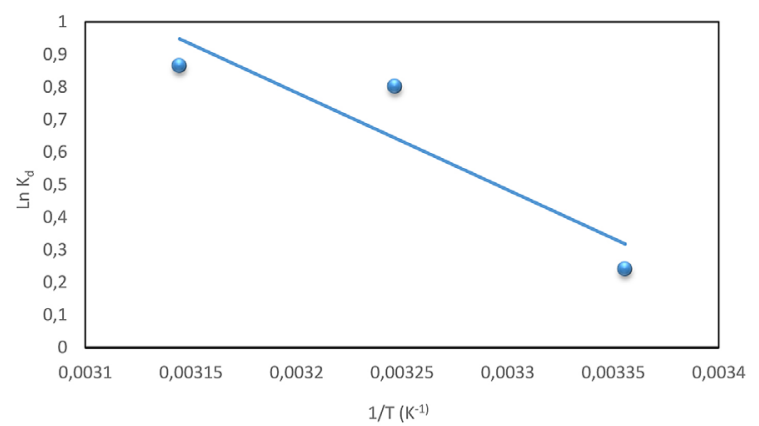

Fig. 4. Vant Hoff's linear plots of $\mathrm{Ln}_{d}$ versus $1 / \mathrm{T}$

Table 2. Thermodynamics parameters calculated for phenol adsorption on gypsum

\begin{tabular}{|l|c|c|}
\hline \multicolumn{1}{|c|}{ Model } & \multicolumn{2}{|c|}{ Kinetic parameters } \\
\hline \multirow{3}{*}{ Pseudo-second-order } & $q_{e}(\mathrm{mmol} / \mathrm{g})$ & 87.72 \\
\cline { 2 - 3 } & $K_{2}(\mathrm{~g} / \mathrm{mmol} \mathrm{min})$ & 4.357 \\
\cline { 2 - 3 } & $\mathrm{R}^{2}$ & 0.9997 \\
\hline \multirow{4}{*}{ Elovich } & $\beta(\mathrm{g} / \mathrm{mmol})$ & 0.0623 \\
\cline { 2 - 3 } & $\alpha(\mathrm{mmol} / \mathrm{g} \mathrm{min})$ & 11.253 \\
\cline { 2 - 3 } Intraparticle diffusion & $\mathrm{R}^{2}$ & 0.9898 \\
\cline { 2 - 3 } & $K_{p i}\left(\mathrm{mmol}^{2} \mathrm{~g} \mathrm{\textrm {min } ^ { 0 . 5 } )}\right.$ & 11.789 \\
\cline { 2 - 3 } & $c_{i}$ & 8.6795 \\
\cline { 2 - 3 } & $\mathrm{R}^{2}$ & 0.9988 \\
\hline
\end{tabular}

energy change for physical adsorption is between -20 and $0 \mathrm{~kJ} / \mathrm{mol}$, but for chemical adsorption it is in the range of -80 to $-400 \mathrm{~kJ} / \mathrm{mol}$ (Babakhouya et al., 2010; Atkins, 1990). This suggests that the adsorption of phenol on gypsum is a physical adsorption process. The positive value of $\Delta \mathrm{H}^{0}$ indicates the phenol adsorption process is endothermic in nature (Adeogun and Balakrishnan, 2015; Babakhouya et al., 2010). The positive $\Delta \mathrm{S}^{0}$ value obtained denotes the increase in the degree of disorderliness of the adsorbed species (AlOthman et al., 2014) and the affinity of the gypsum adsorbent for phenol.

\section{Adsorption kinetics}

Adsorption kinetic models are used to study the adsorption rate and the probable rate governing step. The kinetics of the adsorption of phenol on gypsum was studied using the pseudo-secondorder, Elovich, and intraparticle diffusion models.

The pseudo-second-order is stated as follows (Ho, 2006):

$$
\frac{\mathrm{t}}{\mathrm{q}_{\mathrm{t}}}=\frac{1}{\mathrm{~K}_{2}}+\frac{1}{\mathrm{q}_{\mathrm{e}}} \mathrm{t}
$$

where: $q_{e}$ and $q_{t}$ is the amount of phenol adsorbed per unit mass of the adsorbent at equilibrium and at time, $t(\mathrm{mmol} / \mathrm{g})$.

$K_{2}$ is the pseudo-second-order rate constants $\left(\mathrm{min}^{-1}\right)$.

The pseudo-second-order plot is shown in Fig. 5. The constants, $q_{e}$ and $K_{2}$ (Table 3 ) were evaluated from the slope and intercept of the regression plot of $t / q_{t}$ versus $t$ (Fig. 5), respectively. The value of the regression coefficient, $\mathrm{R}^{2}(0.9997)$ implies that the adsorption kinetic data obeys the pseudo-second-order model more so than other models. A study on the removal of phenol using adsorption onto modified Pistacia mutica shells (Sarvani et al., 2018) also followed the model.

The Elovich kinetic model is expressed as (Riahi et al., 2017; Abdelkreem, 2013):

$$
q_{t}=(1 / \beta) \operatorname{Ln}(\alpha \beta)+(1 / \beta) \operatorname{Ln} t
$$

where: $\alpha$ is the initial adsorption rate ( $\mathrm{mmol} / \mathrm{g} \min )$ and

$\beta$ is related to the extent of surface coverage and the activation energy for chemisorption $(\mathrm{g} / \mathrm{mmol})$. 
Table 3. Comparison of gypsum with other materials for phenol reduction

\begin{tabular}{|c|c|c|c|}
\hline Adsorbent & Maximum removal & Conditions & Reference \\
\hline Pomegranate peel carbon & $95.96 \%(79.97 \mathrm{mg} / \mathrm{g})$ & $\begin{array}{l}\text { phenol concentration = } 50 \mathrm{mg} / \mathrm{l} \text { adsorbent } \\
\text { dosage }=0.4 \mathrm{~g} / \mathrm{l} \\
\text { Time }=120 \mathrm{~min} \\
\mathrm{pH}=7 \\
\text { temperature }=30 \pm 1^{\circ} \mathrm{C} \\
\text { stirring rate }=150 \mathrm{rpm} \\
\text { Speed }=150 \mathrm{rpm} \\
\end{array}$ & Afsharnia et al., 2016 \\
\hline Dates'stones & $99 \%$ & $\begin{array}{l}\text { Phenol concentration }=30 \mathrm{mg} / \mathrm{L} \\
\mathrm{pH}=3 \\
\text { temperature }=50^{\circ} \mathrm{C} \\
\text { mass of activated carbon }=0.2 \mathrm{~g}\end{array}$ & Un et al., 2017 \\
\hline Rhazya stricta carbon & $85 \%$ & $\begin{array}{l}\text { solution } \mathrm{pH}=3 \\
\text { adsorbent dose }=0.5 \mathrm{~g} / \mathrm{l} \text { temperature of } 45^{\circ} \mathrm{C} \\
\mathrm{V}=50 \mathrm{~mL} \\
\text { Contact time }=4 \mathrm{~h} \\
\text { Phenol concentration }=100 \mathrm{mg} / \mathrm{L} \\
\text { Speed }=100 \mathrm{rpm}\end{array}$ & Hegazy et al., 2014 \\
\hline Na-montmorillonite & $100 \%(15 \mathrm{mg} / \mathrm{g})$ & $\begin{array}{l}\mathrm{pH}=5 \\
\text { Volume, } \mathrm{V}=100 \mathrm{~mL} \\
\text { Phenol concentration }=5 \mathrm{mg} / \mathrm{L} \\
\text { Contact time }=180 \mathrm{~min} \\
\text { Temperature }=23^{\circ} \mathrm{C} \\
\text { Speed }=180 \mathrm{rpm}\end{array}$ & Djebbar et al., 2012 \\
\hline Pistacia mutica shells & $99 \%(15.2 \mathrm{mg} / \mathrm{g})$ & $\begin{array}{l}\text { Phenol concentration = } 50 \mathrm{mg} / \mathrm{L} \text { ) Adsorbent } \\
\text { dosage }=1 \mathrm{~g} / \mathrm{L} \\
\mathrm{pH}=4 \\
\text { Contact time }=45 \mathrm{~min} \\
\mathrm{~V}=100 \mathrm{~mL} \\
\text { Speed }=150 \mathrm{rpm}\end{array}$ & Sarvani et al., 2018 \\
\hline Bentonite & $97.9 \%(8.2 \mathrm{mg} / \mathrm{g})$ & $\begin{array}{l}\text { Contact time }=60 \mathrm{~min} \\
\text { Initial phenol concentration }=50 \mathrm{mg} / \mathrm{L} \\
\text { Dosage of bentonite }=1 \mathrm{~g} / \mathrm{L} \\
\mathrm{pH}=4 \\
\text { Temperature }=25^{\circ} \mathrm{C} \\
\mathrm{V}=100 \mathrm{~mL} \\
\text { Speed }=150 \mathrm{rpm}\end{array}$ & $\begin{array}{l}\text { Ahmadi and } \\
\text { Igwegbe, } 2018\end{array}$ \\
\hline Gypsum & $\begin{array}{l}84.25 \%(31.28 \\
\mathrm{mmol} / \mathrm{g})\end{array}$ & $\begin{array}{l}\text { Contact time }=5 \mathrm{~min}, \\
\text { Mass of gypsum }=3 \mathrm{~g} \text {, temperature }=25^{\circ} \mathrm{C} \\
\text { Phenol concentration }=0.3809 \mathrm{~mol} / \mathrm{L} . \\
\mathrm{pH}=7 \\
\mathrm{~V}=250 \mathrm{~mL}\end{array}$ & This study \\
\hline
\end{tabular}

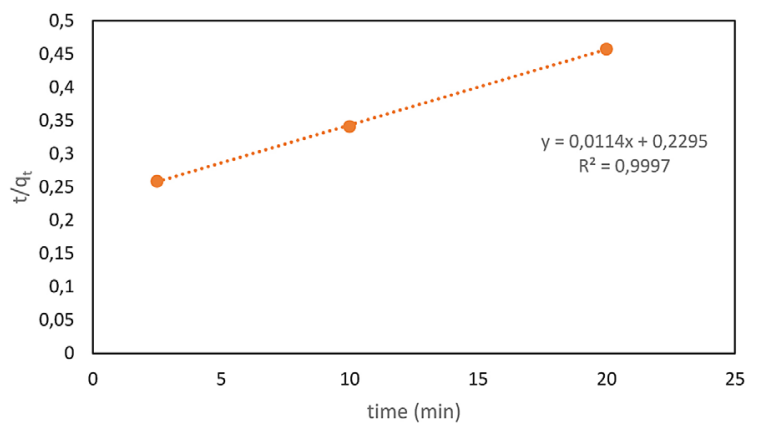

Fig. 5. Pseudo-second-order kinetic model plot of phenol adsorption onto gypsum

The plot of $q_{t}$ versus $L n t$ is shown in Figure 6 . The Elovich constants, $\beta$, and $\alpha$ were obtained from the slope and intercept, respectively. The data fitted well into the model. The studies by Abdelkreem (2013) and Ekpete et al. (2011) followed the Elovich model.
The intraparticle diffusion equation is given as (Igwegbe et al., 2016; Reddy et al., 2012):

$$
q_{t}=k_{p i} t^{0.5}+c_{i}
$$

where: $c_{i}$ is a constant that provides an idea about the thickness of the boundary layer, $k_{p i}$ is the intraparticle diffusion rate con-

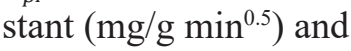

$q_{t}$ is the amount adsorbed $(\mathrm{mmol} / \mathrm{g})$ at time $\mathrm{t}$ ( $\mathrm{min})$.

The graph of $q_{t}$ versus $t^{0.5}$ is represented in Figure 7. The intraparticle constants, $k_{p i}$ and $c_{i}$ were calculated from the slope and intercept, respectively. The data conformed to the intraparticle diffusion model. The plot did not pass through the origin implying that the intra-particle diffusion is not the only rate limiting step (Ma et al., 2013). 


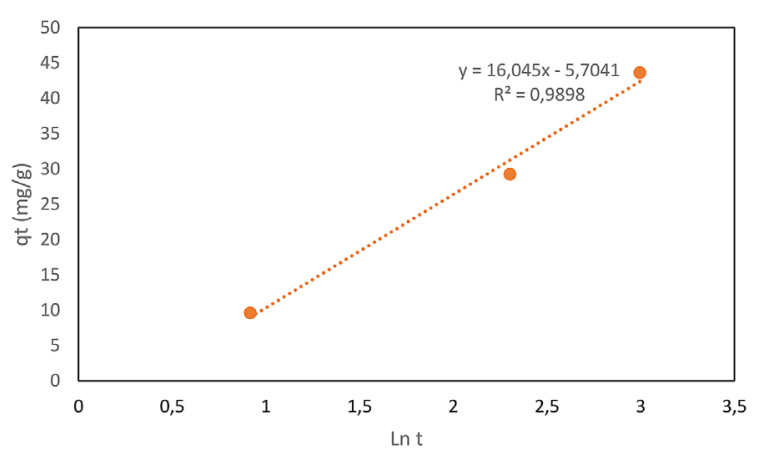

Fig. 6. Elovich kinetic model plot of phenol adsorption onto gypsum

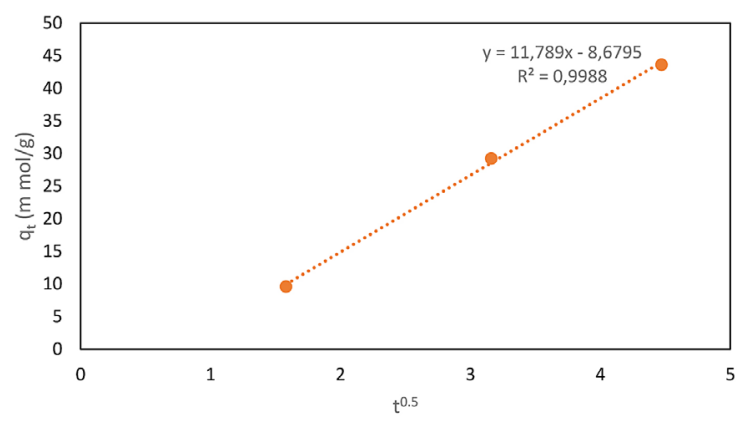

Fig. 7. Intraparticle diffusion plot of phenol adsorption onto gypsum

Generally, the phenol adsorption kinetic data fitted best into the pseudo-second-order kinetic model denoting a chemical adsorption process (Igwegbe et al., 2016).

\section{Comparison with other adsorbents for phenol removal}

The removal efficiencies and the adsorption capacities of phenol removal using different adsorbent materials are presented in Table 3. It indicates that gypsum is a potential material that can be applied for the reduction of phenol in aqueous environments, when compared with other materials.

\section{CONCLUSION}

The effectiveness of the adsorptive removal of phenol from its aqueous solution using gypsum (which is readily available) was investigated. The effect of gypsum mass, contact time and solution temperature on the adsorption process was studied. Phenol removal was found to increase along with adsorbent mass, contact time and temperature. The phenol adsorption process on gypsum was found to be spontaneous and endothermic in nature. The adsorption data fit into the pseudosecond-order, Elovich, and intraparticle diffusion kinetic models. The results obtained from the study showed that gypsum can act as a potential adsorbent for the removal of phenol from its aqueous solutions.

\section{Acknowledgement}

The Authors would like to thank the Tafila Technical University for funding this research project.

\section{REFERENCES}

1. Abdelkreem M (2013) Adsorption of Phenol from Industrial Wastewater Using Olive Mill Waste. APCBEE Procedia 5: 349-357.

2. Adeogun AI, Balakrishnan RB (2017) Kinetics, isothermal and thermodynamics studies of electrocoagulation removal of basic dye rhodamine B from aqueous solution using steel electrodes. Appl Water Sci 7: 1711. https://doi.org/10.1007/ s13201-015-0337-4

3. Afsharnia M, Saeidi M, Zarei A,Narooie MR, Biglari H (2016) Phenol Removal from Aqueous Environment by Adsorption onto Pomegranate Peel Carbon. Electron Physician 8(11): 3248-3256. doi: $10.19082 / 3248$

4. Afsharnia M, Sajjadi SA, Meknati HBA, Qasemi M (2017) Phenol removal by Meliaazedarach seed ash from aqueous solutions. J Health Sci Technol 1(3): 112-118

5. Ahmadi S, Igwegbe CA (2018) Adsorptive removal of phenol and aniline by modified bentonite: adsorption isotherm and kinetics study. Appl Water Sci 8: 170. https://doi.org/10.1007/ s13201-018-0826-3

6. AlOthman ZA, Habila MA, Ali R, Ghafar AA, Eldin Hassouna MS (2014) Valorization of two waste streams into activated carbon and studying its adsorption kinetics, equilibrium isotherms and thermodynamics form ethylene blue removal. Arabian J Chem 7: 1148-1158.

7. Atkins PW (1990) Physical Chemistry. 4th Edn., Oxford University Press, London 884-890.

8. Azevedo EB, Tôrres AR, Aquino Neto FR, Dezotti M (2009) TiO2-Photocatalyzed degradation of phenol in saline media in an annular reactor: hydrodynamics, lumped kinetics, intermediates, and acute toxicity. Braz J Chem Eng 26(1). http:// dx.doi.org/10.1590/S0104-66322009000100008

9. Babakhouya N, Boughrara S, Abad F (2010) Kinetics and thermodynamics of $\mathrm{Cd}(\mathrm{II})$ Ions sorption 
on mixed sorbents prepared from olive stone and date pit from aqueous solution. American Journal of Environmental Sciences 6 (5): 470-476.

10. Baird C (1998) Environmental Chemistry, Freeman, New York.

11. Baldiris-Navarro I, Sanchez-Aponte J, GonzálezDelgado A, Jimenez AR, Acevedo-Morantes M (2018) Removal and biodegradation of phenol by the freshwater microalgae Chlorella vulgaris. Contemporary Engineering Sciences 11(40): 19611970. https://doi.org/10.12988/ces.2018.84201

12. Banat FA, Al-Bashir B, Al-Asheh S, Hayajneh O (2000) Adsorption of phenol by bentonite. Environ Pollut 107(3): 391-8. doi: 10.1016/ S0269-7491(99)00173-6

13. Banerjee S, Chattopadhyaya MC (2017) Adsorption characteristics for the removal of a toxic dye, tartrazine from aqueous solutions by a low cost agricultural by-product. Arabian J. Chem. 10: S1629-S1638. https://doi.org/10.1016/j.arabjc. 2013.06 .005

14. Bazrafshan E, Biglari H, Mahvi A (2012) Performance evaluation of electrocoagulation process for phenol removal from aqueous solutions. Fresenius Environmental Bulletin 21(2): 364-71.

15. Bazrafshan E, Kord Mostafapour F, Faridi H, Zazouli MA (2012) Application of Moringa peregrina seed extract as a natural coagulant for phenol removal from aqueous solutions. Afr J Biotechnol 11(103): 16758-16766.

16. Bello OS, Bello LA, Adegoke KA (2013) Adsorption of dyes using different types of sand: a review. S Afr J Chem 66: 117-129.

17. Benosmane N, Boutemeur B, Hamdi SM, Hamdi M (2018) Removal of phenol from aqueous solution using polymer inclusion membrane based on mixture of CTA and CA, Appl Water Sci 8:17. https://doi.org/10.1007/s13201-018-0643-8

18. Buhani M, Rahmawaty P, Rilyanti SM,Sumadi (2018)Adsorption of phenol and methylene blue in solution by oil palm shell activated carbon prepared by chemical activation. Orient J Chem34(4): 2043-2050. DOI: http://dx.doi.org/10.13005/ ojc/3404043

19. Caetano M, Valderrama C, Farran A, Cortina JL (2009) Phenol removal from aqueous solution by adsorption and ion exchange mechanisms onto polymeric resins. J Colloid Interface Sci338(2): 402-9. doi: 10.1016/j.jcis.2009.06.062

20. Cornelis K, Cornelius SH Jr (1985)Manual of Mineralogy, 20th ed., John Wiley, 352-353.

21. Dakhil IH (2013) Removal of phenol from industrial wastewater using sawdust, International Journal of Engineering and Science 3(1): 25-31.

22. Deng H, Li G, Yang H, Tang J (2010) Preparation of activated carbons from cotton stalk by microwave assisted $\mathrm{KOH}$ and $\mathrm{K} 2 \mathrm{CO} 3$ activation.
Chemical Engineering Journal.163(3): 373-381. DOI:10.1016/j.cej.2010.08.019

23. Djebbar M, Djafri F, Bouchekara M, Djafri A (2012) Adsorption of phenol on natural clay. Appl Water Sci 2: 77. https://doi.org/10.1007/ s13201-012-0031-8

24. Douara N, Bestani B, Benderdouche N, Duclaux L(2016)Sawdust-based activated carbon ability in the removal of phenol-based organics from aqueous media,Desalination and Water Treatment 57(12): 5529-5545. DOI: 10.1080/19443994.2015.1005151

25. Ekpete OA, Horsfall Jnr M, Tarawou T (2011) Sorption kinetic study on the removal of phenol using fluted pumpkin and commercial activated carbon. Int J Biol Chem Sci 5(3): 1143-1152. DOI: 10.4314/ijbcs.v5i3.72243

26. EPA (2015) Update of human health ambient water quality criteria: 2,4-Dimethylphenol 105-67-9, Office of Science and Technology Office of Water, EPA 820-R-15-085.

27. Esplugas S, Giménez J, Contreras S, Pascual E, Rodríguez M (2002) Comparison of different advanced oxidation processes for phenol degradation. Water Research, 36(4): 1034-1042.

28. Feng J, Qiao K, Pei L, Lv J, Xie S (2015) Using activated carbon prepared from Typha orientalisPresl to remove phenol from aqueous solutions. Ecol Eng 84: 209-17. doi: 10.1016/j.ecoleng.2015.09.028.

29. Gholizadeh A, Kermani M, Gholami M, Farzadkia M (2013) Kinetic and isotherm studies of adsorption and biosorption processes in the removal of phenolic compounds from aqueous solutions: comparative study. J Environ Health Sci Eng 11(1): 29. doi: 10.1186/2052-336x-11-29.

30. Gorzin F, Abadi MMBR (2018) Adsorption of $\mathrm{Cr}(\mathrm{VI})$ from aqueous solution by adsorbent prepared from paper mill sludge: Kinetics and thermodynamics studies, Adsorption Science \& Technology 36(1-2) 149-169. DOI: $10.1177 / 0263617416686976$

31. Halhouli KA, Darwish NA, Al-Dhoon NM (1995) Effects of $\mathrm{pH}$ and inorganic salts on the adsorption of phenol from aqueous systems on activated decolorizing charcoal. Sep Sci Technol 30(17): 3313-24. doi: 10.1080/01496399508013147.

32. Hamdaoui M, Hadri M, Bencheqroun Z, Draoui1 K, Nawdali M, Zaitan H, Barhoun A (2018) Improvement of phenol removal from aqueous medium by adsorption on organically functionalized Moroccan stevensite. Mater. Environ Sci 9(4): 1119-1128. https://doi.org/10.26872/jmes.2018.9.4.123

33. Hegazy AK, Abdel-Ghani NT, El-Chaghaby GA (2014) Adsorption of phenol onto activated carbon from Rhazya stricta: determination of the optimal experimental parameters using factorial design. Appl Water Sci 4: 273-281. DOI 10.1007/ 
s13201-013-0143-9

34. Ho Y (2006)Second-order kinetic model for the sorption of cadmium onto tree fern: a comparison of linear and non-linear methods. Water Res 40: 119-125.

35. Igwegbe CA, Onukwuli OD, Nwabanne JT (2016) Adsorptive removal of vat yellow 4 on activated Mucuna pruriens (velvet bean) seed shells carbon. Asian J Chem Sci1: 1-16.

36. Kaczorek E, Smułek W, Zdarta A, Sawczuk A, Zgoła-Grzeskowiak A (2016) Influence of saponins on the biodegradation of halogenated phenols. Ecotoxicol Environ Saf 131:127-134.

37. Khoshnamvand N, Ahmadi S, Mostafapour FK (2017) Kinetic and isotherm studies on ciprofloxacin an adsorption using magnesium oxide nanoparticles. J App Pharm Sci 7(11): 079-083.

38. Kilic M., Apaydin-Varol E., Pütün AE (2011)Adsorptive removal of phenol from aqueous solutions on activated carbon prepared from tobacco residues: Equilibrium, kinetics and thermodynamics, J Hazard Mater 189(1-2): 397-403. https://doi. org/10.1016/j.jhazmat.2011.02.051

39. Kulkarni SJ, Kaware JP (2013) Review on research for removal of phenol from wastewater, International Journal of Scientific and Research Publications 3(4): 1-5.

40. Kumar P, Nikakhtari H, Nemati M, Hill GA (2010) Oxidation of phenol in a bioremediation medium using Fenton's reagent. Environ Technol31(1): 47-52. doi: 10.1080/09593330903338403.

41. Larous S, Meniai A-H (2012) The use of sawdust as by-product adsorbent of organic pollutant from wastewater: adsorption of phenol. Energy Procedia 18:905-914. doi:10.1016/j.egypro.2012.05.105

42. Li H (2014) Adsorption and desorption capacity of methamphetamine in gypsum drywall, MSc. Thesis, Missouri University of Science and Technology.

43. Mahvi AH, Maleki A, Alimohamadi M, Ghasri A (2007) Photo-oxidation of phenol in aqueous solution: Toxicity of intermediates, Korean J Chem Eng 24 (1):79-82.

44. Manshouri M, Daraei H, Yazdanbakhsh AR (2012) The feasibility study of ostrich feathers in removing phenol from aqueous solution. J Kermanshah Univ Med Sci 16(5):359-66.

45. Menkiti MC, Abonyi MN, Aniagor CO (2018) Process equilibrium, kinetics, and mechanisms of ionic-liquid induceddephenolation of petroleum effluent, Water Conservation Science and Engineering. https://doi.org/10.1007/s41101-018-0052-8

46. Mostafa MR, Sarma SE, Yousef AM (1989) Removal of organic pollutants from aqueous solution: Part 1. Adsorption of phenols by activated carbon. Ind J Chem 28A:946 - 1948.
47. Mukherjee S, Kumar S, Misra AK, Fan M (2007) Removal of phenols from water environment by activated carbon, bagasse ash and wood charcoal. Chem Eng J 129(1- 3): 133-42. doi: 10.1016/j. cej.2006.10.030.

48. Olya ME, Pirkarami A (2013) Electrocoagulation for the removal of phenol and aldehyde contaminants from resin effluent. Water Sci Technol68(9):1940-9. doi: 10.2166/wst.2013.439.

49. Petruzzelli G, Scatena M, Rosellini I, Pedron F (2015) The use of compost - red gypsum mixture as a low cost alternative adsorbent for lead. Resources and Environment 5(3): 90-96. DOI: 10.5923/j.re.20150503.02

50. Pourakbar M, Moussavi G, Yaghmaeian K (2018) Enhanced biodegradation of phenol in a novel cyclic activated sludge integrated with a rotating bed bioreactor in anoxic and peroxidase-mediated conditions. RSC Adv. 2018: 86293.

51. Raii M, Minh DP, Sanz FJE, Nzihou A (2014)Lead and Cadmium removal from aqueous solution using an industrialgypsum by-product. Procedia Engineering 83:415 - 422 .

52. Rauf MA, Shehadeh L, Ahmed A, Al-Zamly A(2009) Removal of methylene blue from aqueous solution by using gypsum as a low cost adsorbent. World Academy of Science, Engineering and Technology 3:540-545.

53. Reddy MCS, Sivaramakrishna L, Reddy AV (2012) The use of an agricultural waste material, Jujuba seeds for the removal of anionic dye (congo red) from aqueous medium. J Hazard Mater 203-204:118-127. http://dx.doi.org/10.1016/j. jhazmat.2011.11.088

54. Roostaei N, Tezel FH (2004) Removal of phenol from aqueous solutions by adsorption. J Environ Manage 70(2):157-64. doi: 10.1016/j.jenvman.2003.11.004.

55. Radnia H, Ghoreyshi AA, Younesi H, et al. (2012) Adsorption of $\mathrm{Fe}(\mathrm{II})$ ions from aqueous phase by chitosan adsorbent: Equilibrium, kinetic, and thermodynamic studies. Desal Water Treat 50:348-359.

56. Rahmani A, Samadi MT, Enayati MA (2008) Investigation of photocatalytic degradation of phenol through UV/TiO2 process in aquatic solutions. J Res Health Sci 8:32-37

57. Riahi K, Chaabane S, Thayer BB (2017) A kinetic modeling study of phosphate adsorption onto Phoenix dactylifera L. date palm fibers in batch mode. Journal of Saudi Chemical Society 21:S143-S152.

58. Rodrigues LA, da Silva ML, Alvarez-Mendes MO, dos Reis Coutinho A, Thim GP (2011) Phenol removal from aqueous solution by activated carbon produced from avocado kernel seeds. Chemical Engineering Journal 174(1):49-57. DOI:10.1016/j. cej.2011.08.027 
59. Roostaei N, Tezel FH (2004) Removal of phenol from aqueous solutions by adsorption. J Environ Manage 70(2):157-64. doi: 10.1016/j.jenvman.2003.11.004.

60. Rubalcaba A, Suárez-Ojeda ME, Stüber F, Fortuny A, Bengoa C, Metcalfe I, Font J, Carrera J, Fabregat A (2007) Phenol wastewater remediation: advanced oxidation processes coupled to a biological treatment. Water Science \& Technology 55(12):221-227.

61. Salari S, Afsharnia M, Moteallemi A, Ghasemi M (2018) Evaluation of removal efficiency of phenol from synthetic aqueous solutions by Citrullus colocynthis seed ash, Environmental Health Engineering and Management Journal 5(1):49-55.

62. Sarvani R, Damani E, Ahmadi S (2018) Adsorption isotherm and kinetics study: removal of phenol using adsorption onto modified Pistacia mutica shells. Iranian Journal of Health Sciences 6(1): 33-42.

63. Sahu O, Rao DG,Gabbiye N, Engidayehu A,TeshaleF (2017) Sorption of phenol from synthetic aqueous solution by activated saw dust: Optimizing parameters with response surface methodology. Biochem Biophys Rep 12:46-53. doi:10.1016/j.bbrep.2017.08.007

64. Senthilvelan T, Kanagaraj J, Panda RC, Mandal AB (2014) Biodegradation of phenol by mixed microbial culture: an eco-friendly approach for the pollution reduction. Clean Technol. Environ. Policy 16:113-126.

65. Senturk HB, Ozdes D, Gundogdu A, Duran C, Soylak M (2009) Removal of phenol from aqueous solutions by adsorption onto organomodified Tirebolu bentonite: equilibrium, kinetic and thermodynamic study. J Hazard Mater 172(1):353-62. doi: 10.1016/j.jhazmat.2009.07.019.

66. Sharan R, Singh G, Gupta SK (2009) Adsorption of phenol from aqueous solution onto fly ash from a thermal power plant. Adsorption Science \& Technology 27:267-279.https://doi. org/10.1260/026361709789868875

67. Sogut EG, Caliskan N (2017)Isotherm and kinetic studies of $\mathrm{Pb}(\mathrm{II})$ adsorption on raw and modified diatomite by using non-linear regression method. Fresenius Environmental Bulletin 26(4):2721-2729.

68. Srivastava VC, Swamy MM, Mall ID, Prasad B, Mishra IM (2006) Adsorptive removal of phenol by bagasse fly ash and activated carbon: equilib- rium, kinetics and thermodynamics. Colloids Surf A Physicochem Eng Asp 272(1-2):89-104. doi: 10.1016/j.colsurfa.2005.07.016

69. Tao Y, Cheng ZL, Ting KE, Yin XJ (2013) Photocatalytic degradation of phenol using a nanocatalyst: the mechanism and kinetics, Journal of Catalysts. Article ID 364275, 6 pages. http://dx.doi. org/10.1155/2013/364275

70. Uddin MT, Islam MS, Islam MA, Abedin MZ (2008) Uptake of phenol from aqueous solution by burned water hyacinth, Polish Journal of Chemical Technology 10(2):43 - 49.

71. Un UT, GulA (2017)Removal of Phenol by Adsorption. International Journal of Advances in Science Engineering and Technology 5(2):38-40

72. Villegas LGC, Mashhadi N, Chen M, Mukherjee D, TaEylor K, Biswas N (2016) A short review of techniques for phenol removal from wastewater. Current Pollution Reports 2:157. https://doi. org/10.1007/s40726-016-0035-3.

73. Wu C, Liu X, Wei D, Fan J, Wang L (2001) Photosonochemical degradation of phenol in water. Water Res 35(16): 3927-33. doi: 10.1016/ S0043-1354(01)00133-6.

74. Yan J, Jianping W, Jing B, Daoquan W, Zongding H (2006) Phenol biodegradation by the yeast Candida tropicalis in the presence of m-cresol. Biochemical Engineering Journal 29(3): 227-234.

75. Yan MA, Naiyun GAO, Wenhai CHU, Cong LI (2013) Removal of phenol by powdered activated carbon adsorption. Front Environ Sci Eng 7(2): 158-165. DOI 10.1007/s11783-012-0479-7

76. YavuzY, Savas Koparal A, Bakir Ögütveren Ü (2007) Phenol removal through chemical oxidation using Fenton reagent. Chemical Engineering Technology 30(5):583-586. https://doi.org/10.1002/ceat.200600377

77. Zarei A, Bazrafshan E, Faridi H, Khaksefidi R, Alizadeh M (2013) The evaluation of removal efficiency of phenol from aqueous solutions using Moringa peregrinatree shell ash. Iranian Journal of Health Sciences 1(1):65-74. doi: 10.18869/acadpub.jhs.1.1.65.

78. Zazouli MA, Taghavi M (2012) Phenol removal from aqueous solutions by electrocoagulation technology using iron electrodes: effect of some variables. Journal of Water Resource and Protection 4:980-983. http://dx.doi.org/10.4236/ jwarp.2012.411113 